\title{
European Stroke Initiative: The Stroke Summer School
}

\author{
Michael Brainin \\ Donau-Universität und Donauklinikum Maria Gugging, Maria Gugging, Österreich
}

\section{History}

The Stroke Summer School is an annual educational project introduced by the European Stroke Initiative in 1997. It has become the leading postgraduate educational stroke programme in Europe.

The Summer Schools aim to provide up-to-date information on stroke research and clinical care to young scientists and clinicians. The intention is to have students participate in lecture programmes and give them the opportunity to build networks by creating a stimulating environment in which young scientists from all over Europe can exchange their experiences and ideas. The objective is to make stroke care and research an international experience with the possibilities of creating small, efficient networks and to mingle with the leading researchers in the field who make themselves available for lively discussions with the students. Thus, for a whole week, lectures and seminars are held at a faculty and a social programme furthers informal contacts and cultural exchange.

The EUSI Stroke Summer School has an 8-year history. It was founded by Professor Kjell Asplund and is continued by the EUSI at different locations throughout Europe.

EUSI Summer Schools

\begin{tabular}{|c|c|c|c|}
\hline Year & Location & Country & Organizer \\
\hline 1997 & Umea & Sweden & Kjell Asplund \\
\hline 1998 & Heidelberg & Germany & $\begin{array}{l}\text { Werner Hacke/ } \\
\text { Michael Hennerici }\end{array}$ \\
\hline 1999 & Edinburgh & UK & Charles Warlow \\
\hline 2000 & Rome & Italy & Cesare Fieschi \\
\hline 2001 & Debrecen & Hungary & Laszlo Csiba \\
\hline 2002 & Helsinki & Finland & Markku Kaste \\
\hline 2003 & Paris & France & Marie G. Bousser \\
\hline 2004 & Krems & Austria & Michael Brainin \\
\hline
\end{tabular}

In 2004, the Danube University in Krems, Austria, hosted the event. Only an hour's drive from the capital Vienna, it is located in the middle of some of the most beautiful vineyards of the Danube region, with medieval castles towering the meandering river. The region is ideal for small congresses and teaching projects. The state-funded university hosts a young but ambitious clinical neuroscience centre, which focuses on postgraduate clinical training programmes.

\section{A Challenging Task for an International Faculty}

As Austria is the country of music, it was appropriate to have a lecture on 'Music and the Brain', given by Professor Jürg Kesselring from Valens (Switzerland), on the opening night. Then a string quartet featuring 3 neurologists and 1 internist (Verena and Jürg Kesselring as well as Jutta and Hans Lassmann) gave a moving performance of Brahms' Bagatelles.

Highlights of the teaching programme were lectures by Professor Kaste, Finland (co-editor of Stroke), and Professor Röggla, Austria (previously European editor of The Lancet), on 'How to write a scientific paper and get it accepted'. Professor Sandercock, UK, gave a seminar on 'Clinical Epidemiology' and Professor Tuomilehto, Finland, on 'Strategies of Prevention'. The focus of the Summer School was on the critical appraisal of clinical studies, with a lot of room given to discussion and exchange of ideas. Other highlights included new and exciting results of recent thrombolysis studies, which were discussed with Professor Hacke, Germany, and a superb anatomical-clinical lecture on posterior circulation stroke, given by Professor Bogousslavsky, Switzerland.

The faculty was chosen to present all aspects of stroke care and stroke research, including basic research and rehabilitation. Clinical focus included prevention, acute interventions and therapy as well as post-stroke care. Finally, Austrian stroke researchers were able to present their own research and the very advanced system of stroke units within the country. The full lecture programme can be downloaded at: http://www.donau-uni.ac.at/de/studium/fachabteilungen/umwelt/zentren/neuro/index.php

\begin{tabular}{ll}
\hline KARGER & $\begin{array}{l}\text { ( ) 2005 S. Karger AG, Basel } \\
1015-9770 / 05 / 0196-0359 \$ 22.00 / 0\end{array}$ \\
$\begin{array}{l}\text { Fax +41 61306 1234 } \\
\text { E-Mail karger@karger.ch } \\
\text { www.karger.com }\end{array}$ & $\begin{array}{l}\text { Accessible online at: } \\
\text { www.karger.com/ced }\end{array}$
\end{tabular}



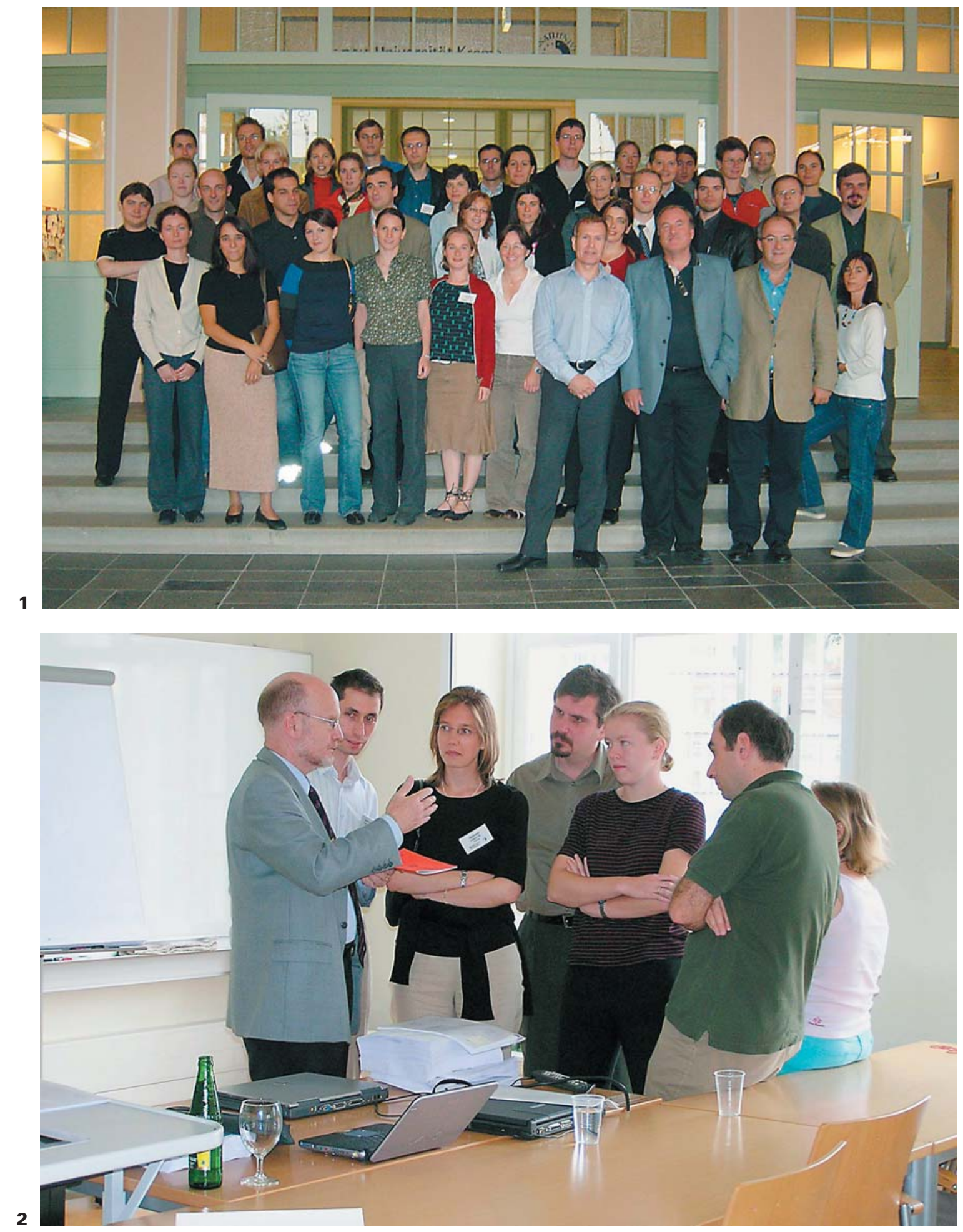

Fig. 1. Thirty-nine participants from 19 countries attended the 2004 EUSI Stroke Summer School at the Danube University in Krems, Austria.

Fig. 2. Former EUSI chairman Prof. Markku Kaste (left) from Helsinki, Finland, in an after-lecture discussion in Krems, Austria. 
There were informal tests for each topic, mostly in multiplechoice format. Every speaker was asked to bring one 'unclear or difficult case' as part of a quiz for the students.

Forthcoming Summer Schools

2005: Stockholm, Sweden

This year's Summer School will be held in Stockholm, organized by Prof. Nils G. Wahlgren. 2005

9th EUSI Stroke Summer School: Stockholm June 26-July 2,

http://www.strokeupdate.org/ESSUS/ESSUS.htm.

2006: Cambridge, UK

In 2006 the EUSI Stroke Summer School will be held in Cambridge, UK, from September 10 to16. It will be organized by Prof. Jean-Claude Baron.

\section{Applications}

EUSI pays for tuition, accommodation, meals, coffee breaks and the social programme. Participants cover their travel fares as well as any personal expenses during the stay.

Students are selected on the basis of their application, which should include:

an informal letter explaining why they want to participate and how this fits into their work and career;

a short curriculum vitae;

a letter of support, either from their head of department or a known researcher in the field from their own country.

Details may vary, so please consult the specific homepage before applying.

If you have any questions about participating in the next Summer School, please contact the organizer, Prof. Nils G. Wahlgren, directly via his homepage and e-mail. If you have any other questions, please contact the Secretary of the EUSI, Prof. Michael Brainin, at: michael.brainin@donau-uni.ac.at

Prof. Werner Hacke, Chairman EUSI

Prof. Michael Brainin, Secretary EUSI

Prof. Michael Brainin

Donau-Universität und Donauklinikum Maria Gugging

AT-3400 Maria Gugging (Austria)

Tel. +43224390555 379, Fax +43224390555 338

E-Mail michael.brainin@donau-uni.ac.at

\section{EUSI Stroke Summer School 2004: An Insider's View}

In September 2004, 39 participants from all over Europe (and one from Brazil!) assembled in Krems, Austria, for the 8th European Stroke Summer School. The course started with an inspiring lecture on 'Music and the brain', given by Jürg Kesselring, and we were treated to a neurological quartet at the end of the evening. Little did we know that the course would end with another musical evening (not quite of the same calibre) as we, the students, thanked the organisers in a rather unforgettable way with a rendition of 'Stroke'.

The programme had been extremely well organised by Professor Michael Brainin and his team. Lectures ranged from details on experimental work to setting up a randomised controlled trial. We learnt about stroke units and rehabilitation and were given invaluable guidance on how to write a clinical paper and, a topic close to all of our hearts, how to get it accepted... The whole week was an incredible opportunity to learn from real experts in stroke and to question them about their individual specialist fields. Discussions were lively and were often continued during the break, resulting in ideas of research and collaborations. The Summer School also provided the opportunity to meet, discuss, debate and learn from other young neurologists.

Most of the time, we live in our wards and labs in a kind of autistic way: you do not understand what the other departments do and fear the competition... This kind of meeting gives you the chance to exchange, learn and get more and more motivated to share your knowledge and your questions! We also gained an insight into stroke care in different parts of Europe and their variations: it was very interesting to learn from neurologists from the eastern countries. Maybe in the future, we will also get the chance to gather people from Asia.

The week was busy and hard work but the setting was very pleasant. Krems lies by the Danube and the university is brand-new and very welcoming. There was time to learn and time to relax. The social programme was as diverse as the lectures. We experienced the local gallery, the fine wines and knödels (dumplings), and even took a bike trip along the Danube. In all, the week was an inspiring and enriching experience and provided a platform from which we hope networks have been set up that will take stroke research and care to even greater heights. UK

Ingrid Kane, Stroke research fellow, University of Edinburgh,

Charlotte Cordonnier, Stroke Unit, University of Lille, France 